\title{
PERAN BAITUL MALL WATTAMWIL SEBAGAI UPAYA PENGENTASAN KEMISKINAN MELALUI PENGEMBANGAN USAHA MIKRO KECIL DAN MENENGAH
}

\author{
SUPANJI SETYAWAN*, CHAIDIR ISWANAJI \\ Universitas Tidar \\ *Email: supanji@untidar.ac.id
}

\begin{abstract}
Poverty is one of the macroeconomic indicators in which Indonesia's economic development in aggregate shows a good picture and a decrease in the poverty level of the poor, but in terms of economic structure, segments of Indonesian society are still relatively lagging behind and relatively do not get real benefits from the results of development. Magelang Regency is one of the districts that have poverty problems. This poverty problem can be overcome by developing micro, small and medium enterprises (MSMEs), especially in the industrial sector, where this sector is the leading sector in Magelang Regency. The purpose of this study was to determine the effect of financing on the income of MSEs as customers of BMT Bima industrial business group and how the role of BMT in overcoming the problem of poverty through the functions of baitul mall and baitul tamwil. This study uses a simple linear regression analysis tool. The results obtained (1) the financing variable does not have a significant effect on the income variable of MSME customers of BMT Bima Magelang industrial business group, this is because there are still customers who use financing for personal economic activities, (2) BMT is able to reduce poverty levels by providing assistance that comes from zakat, infaq, sadaqah, and waqf and still persists by providing financing to MSME customers of the BMT Bima Magelang industry group.
\end{abstract}

Keywords: Poverty, MSMEs, Financing, Income

\section{PENDAHULUAN}

Kemiskinan merupakan salah satu indikator makro ekonomi yang menjadi masalah klasik dan hampir dikatakan akan tetap menjadi sebuah kenyataan abadi dalam kehidupan manusia. Karena merupakan indikator makro ekonomi, sudah barang tentu menjadi indikator pembangunan dan akan lahir sebagai dampak dari proses pembangunan. Masalah kemiskinan di Indonesia telah menjadi topik pembicaraan dan fokus kebijakan sejak pemerintah kolonial Belanda meluncurkan program anti kemiskinan melalui kebijakan "politik etis". Laporan dari Bank Dunia (2010) adalah hampir setengahnya dari penduduk di Indonesia hidup miskin atau rentan terhadap kemiskinan. Dengan kondisi hampir $42 \%$ rumah tangga hidup diantara garis kemiskinan US\$1 dan US\$2 per hari, terlalu

* Corresponding author's e-mail: supanji@untidar.ac.id

http://openjournal.unpam.ac.id/index.php/JIA 
Jurnal Ilmiah Akuntansi Universitas Pamulang - Vol. 9, No. 2 Juli 2021 - Setyawan \& Iswanaji

banyak rakyat Indonesia yang sangat rentan jatuh miskin. Kemiskinan sudah sejak lama menjadi masalah bangsa Indonesia, dan hingga sekarang masih belum menunjukkan tanda-tanda menghilang. Angka statistik terus saja memberikan informasi masih banyaknya jumlah penduduk miskin (Sholihah dkk, 2019). Meskipun telah lama hidup di tengah- tengah masyarakat Indonesia dan berupaya untuk dihapuskan, namun masalah ini masih saja menjadi polemik dan tetap hidup berdampingan dengan bangsa Indonesia.

Pemahaman tentang profil kemiskinan merupakan prasyarat bagi ketepatan strategi pengentasan kemiskinan. Sumodiningrat, Santoso, dan Maiwan (1998) dalam Itang (2015) mengatakan bahwa salah satu masalah kemiskinan adalah tertutupnya akses berbagai peluang kerja hal ini disebabkan karena sempitnya lapangan pekerjaan yang tidak sebanding dengan banyaknya jumlah angkatan kerja. Kuncoro (2000) mengatakan bahwa salah satu penyebab adanya kemiskinan adalah ketidakseimbangan pola kepemilikan sumberdaya sehingga terdistribusi tidak normal serta jumlah dan kualitasnya yang rendah. Kemiskinan yang terjadi di Indonesia hampir menyeluruh di semua provinsi bahkan kabupaten atau kota meskipun jumlahnya berbeda antar daerah satu dengan yang lainnya. Kabupaten Magelang menjadi salah satu kabupaten yang berada di Jawa Tengah yang juga mengalami masalah kemiskinan. Publikasi Pemerintah Kabupaten Magelang (2018) mengatakan bahwa dari pemetaan kemiskinan yang dilaksanakan oleh TKPK (Tim Koordinasi Penanggulangan Kemiskinan) Provinsi Jawa Tengah Tahun 2013, Kabupaten Magelang termasuk dalam kategori tingkat kemiskinan sedang. Masalah kemiskinan tersebut menjadi salah satu bahan dalam membuat program pengentasan kemiskinan, hingga ditemukan salah satu cara untuk menanggulangi kemiskinan tersebut adalah dengan mengembangkan dan menjamin keberlanjutan usaha mikro dan keci. Sebab sesuai dengan kenyataan bahwa UMKM merupakan penggerak utama sektor riil yang berpengaruh langsung terhadap pertumbuhan ekonomi.

Berdasarkan Undang-Undang Nomor 20 Tahun 2008 tentang Usaha Mikro Kecil dan Menengah, usaha mikro adalah usaha produktif milik orang perorangan dan/atau badan usaha perorangan yang memenuhi kriteria usaha mikro. Usaha Kecil adalah usaha ekonomi produktif yang berdiri sendiri, yang dilakukan oleh orang perorangan atau badan usaha yang bukan merupakan anak perusahaan atau bukan cabang perusahaan yang dimiliki, dikuasai, atau menjadi bagian baik langsung maupun tidak langsung dari usaha menengah atau usaha besar yang memenuhi kriteria usaha kecil. Usaha Menengah adalah usaha ekonomi produktif yang berdiri sendiri, yang dilakukan oleh orang perorangan atau badan usaha yang bukan merupakan anak perusahaan atau cabang perusahaan yang dimiliki, dikuasai, atau menjadi bagian baik langsung maupun tidak langsung dengan usaha kecil atau usaha besar dengan jumlah kekayaan bersih atau hasil penjualan tahunan sebagaimana diatur dalam undang- undang. Usaha Mikro, Kecil, dan Menengah bertujuan menumbuhkan dan mengembangkan usahanya dalam rangka membangun perekonomian nasional berdasarkan demokrasi ekonomi yang berkeadilan.

Meskipun UMKM mampu menjadi penggerak sektor riil namun pada nyatanya masih terdapat permasalahan yang dihadapi yaitu permodalan. Kemudian hadirlah lembaga keuangan mikro syariah yang membantu permasalahan klasik UMKM, di mana Baitul Mall Wattamwil (BMT) menjadi 
Jurnal Ilmiah Akuntansi Universitas Pamulang - Vol. 9, No. 2 Juli 2021 - Setyawan \& Iswanaji

salah satu Lembaga Keuangan Mikro Syariah (LKMS) yang menyediakan dan membantu modal bagi para UMKM. BMT adalah salah satu lembaga keuangan mikro syariah yang terdiri dari dua istilah, yaitu baitul maal dan baitul tamwil. Baitul maal lebih mengarah pada usaha-usaha pengumpulan dan penyaluran dana yang non profit, seperti zakat, infaq, shadaqah. Sedangkan baitul tamwil sebagai usaha pengumpulan dan penyaluran dana komersial. Usaha-usaha tersebut menjadi bagian yang tidak terpisahkan dari BMT sebagai lembaga pendukung kegiatan ekonomi msayarakat kecil dengan berlandaskan syariah.

Layanan yang diberikan BMT salah satunya adalah pembiayaan. Pembiayaan adalah pendanaan yang diberikan oleh suatu pihak kepada pihak lain untuk mendukung investasi yang telah direncanakan, baik dilakukan sendiri atau oleh lembaga (Muhammad, 2016). Sehingga pada akhirnya dari pembiayaan yang diberikan oleh BMT dapat digunakan oleh nasabah untuk meningkatkan pendapatan. Mankiw (2006) berpendapat bahwa pendapatan perorangan adalah pendapatan yang diterima oleh rumah tangga dan usaha yang bukan perusahaan.

BMT Bima Kabupaten Magelang merupakan salah satu LKMS yang berbadan hukum koperasi. Jumlah nasabah di tahun 2018 mencapai angka 4000 unit usaha. Layanan yang diberikan oleh BMT Bima sama dengan layanan yang diberikan oleh lembaga keuangan yang lain, salah satunya adalah pemberian pembiayaan kepada para nasabah.

Tabel 1. Rekapitulasi Total Penyaluran Pembiayaan BMT Bima Kabupaten Magelang Periode 2018 Berdasarkan Kelompok Jenis Usaha

\begin{tabular}{|c|c|c|c|c|c|}
\hline \multirow{3}{*}{ No } & \multirow{3}{*}{ Usaha } & \multicolumn{4}{|c|}{ Rata-Rata Pembiayaan } \\
\hline & & \multicolumn{3}{|c|}{ Pembiayaan 2018} & \\
\hline & & Tot & (Rp) & $(\%)$ & \\
\hline 1 & Pertanian & 1.555 & 17.690 .933 .912 & $25,19 \%$ & 11.376 .806 \\
\hline 2 & Perdagangan & 1.424 & 24.937 .062 .025 & $35,50 \%$ & 17.511 .982 \\
\hline 3 & Perindustrian & 239 & 2.977.269.459 & $4,24 \%$ & 12.457 .194 \\
\hline 4 & Jasa & 1.006 & 19.871.520.309 & $28,29 \%$ & 19.753 .002 \\
\hline 5 & Lain-lain & 346 & 4.548 .326 .697 & $6,48 \%$ & 13.145 .453 \\
\hline \multirow[t]{2}{*}{6} & $\mathrm{QH}$ & 231 & 213.684 .000 & $0,30 \%$ & 925.039 \\
\hline & Jumlah & 4.801 & 70.238 .796 .402 & $100,00 \%$ & \\
\hline \multicolumn{3}{|c|}{ Rata-rata pembiayaan } & & & Rp14.630.035 \\
\hline
\end{tabular}

Sumber: Data Pembiayaan BMT Bima Muntilan

Keberadaan BMT Bima mampu membantu perekonomian masyarakat dalam memberikan pembiayaan terutama untuk usaha mikro kecil dan menengah yang semakin banyak jumlahnya, tentunya diharapkan membantu permasalahan permodalan usaha mikro kecil yang berada di sekitar BMT Bima. Kepercayaan ini didukung dengan diperolehnya KSP Award oleh BMT Bima. Tahun 2014 ditetapkannya BMT Bima sebagai Nazhir Wakaf Uang dari Deputi Bidang Pembiayaan KEMENKOP UKM RI dan di tahun 2015 diberikannya sertifikat kesehatan dari Sekretaris Kementerian Koperasi dan UMKM Republik Indonesia. 
Jurnal Ilmiah Akuntansi Universitas Pamulang - Vol. 9, No. 2 Juli 2021 - Setyawan \& Iswanaji

Salah satu kelompok usaha yang menjadi nasabah BMT Bima Magelang adalah perindustrian. Kelompok usaha ini jumlahnya memang tidak sebanyak kelompok usaha pertanian dan perdagangan tetapi Pujianto dari Dinas Koperasi dan UMKM Kabupaten Magelang (2014) menyatakan bahwa kelompok ini menjadi salah satu sektor unggulan yang ada di Kabupaten Magelang. Selain itu, karena memang Kabupaten Magelang menjadi salah satu wilayah transit bagi wisatawan Yogyakarta dan Semarang.

Berdasarkan latar belakang penelitian di atas, maka pertanyaan penelitian sebagai berikut:

1. Apakah pembiayaan dapat mempengaruhi pendapatan usaha mikro kecil dan menengah pada kelompok usaha perindustrian?

2. Bagaimanakah peran lembaga keuangan mikro syariah (BMT) dalam pengentasan kemiskinan melalui Baitul Mall dan Baitul Tamwil di BMT Bima Kabupaten Magelang?

\section{TINJAUAN PUSTAKA}

Menurut Amalia (2009) Baitul Maal wa at-Tamwil (BMT) adalah lembaga swadaya masyarakat, dalam artian, didirikan dan dikembangkan oleh masyarakat. BMT merupakan salah satu lembaga keuangan syariah yang ada di Indonesia yang beroperasi berdasarkan prinsip-prinsip syariah dengan dua fungsi utama yaitu baitul maal dan baitul tamwil (Soemitra, 2009). BMT menjadi salah satu lembaga keungan syariah yang melindungi masyarakat mene-ngah kebawah dari sistem bunga yang diterapkan oleh lembaga konvensional serta dari rentenir yang mematok bunga tinggi pada nasabahnya (Prastiawati, 2016). Abdad (2003) mendefinisikan bahwa baitul mal' adalah suatu lembaga keuangan yang dibentuk pemerintahan Islam guna mengatur segala aktivitas perputaran keuangan, baik mulai penerimaan, penyimpanan, maupun pendistribusian untuk kepentingan kesejahteraan masyarakat berdasarkan Syariat Islam.

Pembiayaan yaitu pendanaan yang diberikan oleh suatu pihak kepada pihak lain untuk mendu-kung investasi yang telah direncanakan, baik di-lakukan sendiri maupun lembaga (Muhammad, 2005). Menurut Undang-Undang Perbankan Syariah No. 21 Tahun 2008 Pasal 1 No. 25, dinyatakan bahwa: Pembiayaan adalah penyediaan dana atau tagihan yang dipersamakan dengan itu berupa:

1. transaksi bagi hasil dalam bentuk mudharabah dan musyarakah;

2. transaksi sewa-menyewa dalam bentuk ijarah atau sewa beli dalam bentuk ijarah muntahiya bittamlik;

3. transaksi jual beli dalam bentuk piutang murabahah, salam, dan istishna ${ }^{\text {ee }}$

4. transaksi pinjam meminjam dalam bentuk piutang qardh; dan

5. transaksi sewa-menyewa jasa dalam bentuk ijarah untuk transaksi multijasa berdasarkan persetujuan atau kesepakatan antara Bank Syariah dan/atau UUS dan pihak lain yang mewajibkan pihak yang dibiayai dan/atau diberi fasilitas dana untuk mengembalikan dana tersebut setelah jangka waktu tertentu dengan imbalan ujrah, tanpa imbalan, atau bagi hasil. 
Jurnal Ilmiah Akuntansi Universitas Pamulang - Vol. 9, No. 2 Juli 2021 - Setyawan \& Iswanaji

Undang-Undang Nomor 20 Tahun 2008 Tentang Usaha Mikro Kecil dan Menengah, usaha mikro adalah usaha produktif milik orang perorangan dan/atau badan usaha perorangan yang memenuhi kriteria usaha mikro. Semua keberhasilan yang telah dicapai oleh UMKM memiliki titik kelemahan yang harus segera diselesaikan meliputi kurangnya permodalan baik jumlah maupun sumbernya, kurangnya kemampuan manajerial dan minimnya keterampilan pengoperasi dalam mengorganisir dan terbatasnya pemasaran merupakan hal yang mendasar selalu dihadapi oleh semua UMKM dalam merintis sebuah usaha bisnis untuk dapat berkembang (Suci, 2017).

\section{METODE PENELITIAN}

Bentuk penelitian dalam penelitian ini adalah metode deskriptif dengan pendekatan kuantitatif. Populasi dalam penelitian ini adalah nasabah kelompok usaha perindustrian sejumlah 239 nasabah. Berdasarkan populasi tersebut, diambel sampel secara random sejumlah 150 orang. Prosedur dalam penelitian ini adalah peneliti mencari data di website resmi BMT Bima Magelang, penyebaran kuosioner ke nasabah kelompok usaha perindustrian. Setelah data diperoleh kemudian dihitung dan diolah menggunakan SPSS 19.0.

Dalam penelitian ini, data yang digunakan adalah data sekunder dan data primer. Data sekunder adalah data yang dikumpulkan oleh lembaga pengumpul data dan dipublikasikan kepada masyarakat pengguna data. Data sekunder berupa laporan pembiayaan BMT Bima Magelang tahun 2018, data kemiskinan yang diperoleh dari Badan Pusat Statistik dan data UMKM Kabupaten Magelang. Sedangkan untuk data primer adalah data yang diperoleh langsung dari objek penelitian. Data primer yang diperoleh dalam penelitian ini adalah dari nasabah BMT Bima Magelang kelompok usaha perindustrian dengan penyebaran kuesioner.

Analisis data adalah sebuah metode yang akan menjadi dasar bagi penarikan kesimpulan terhadap data yang sudah terkumpul. Dalam penelitian ini digunakan analisis regresi linear sederhana dan uji statistik.

a. Model regresi linear sederhana digunakan untuk menguji pengaruh satu variabel independen terhadap satu variabel dependen dan umumnya dinyatakan dalam persamaan sebagai berikut $\mathrm{Y}=\mathrm{a}+\mathrm{bX}$

b. Uji statistik dilakukan dengan tujuan untuk membuktikan ada tidaknya korelasi antara variabel independen dengan variabel dependen. Dari hasil regresi sederhana akan diketahui besarnya koefisien masing-masing variabel. Dari besarnya koefisien akan dilihat adanya hubungan dari variabel- variabel bebas, Uji statistik antara lain uji $t$ dan uji $\mathbf{R}^{2}$.

\section{HASIL DAN PEMBAHASAN}

Hasil Analisis statistic deskriptif dapat digambarkan sebagai berikut: 
Jurnal Ilmiah Akuntansi Universitas Pamulang - Vol. 9, No. 2 Juli 2021 - Setyawan \& Iswanaji

Tabel 2 Hasil Uji Statistik Deskriptif

\begin{tabular}{lccccc}
\hline & N & Minimum & Maxsimum & Mean & Std. Deviation \\
\hline PEM & 150 & 1.8 & 127.7 & 15.626 & 17.8986 \\
\hline Valid N (listwise) & 150 & & & & \\
\hline \multicolumn{2}{c}{ Sumber: SPSS 19.0 (2019), data diolah }
\end{tabular}

Berdasarkan tabel 2 tersebut dapat dilihat jumlah data penelitian sebanyak 150 yang berasal dari sampel penelitian. Terdapat hasil mean, nilai minimum, nilai maksimum, dan standar deviasi dari variabel penelitian yang akan dijelaskan, sebagai berikut :

Hasil analisis statistik deskriptif terhadap pembiayaan menunjukan nilai minimum 1.8 dan nilai maksimum 127.7 dengan rata-rata 15.626 dan standar deviasi sebesar 17.8986.

Hasil Analisis Regresi Pendapatan Nasabah Kelompok Usaha Perindustrian BMT Bima Magelang

Tabel 3 Hasil Regresi

\begin{tabular}{lllll}
\hline \multicolumn{1}{c}{ Independen } & Koefisien & $\begin{array}{l}\text { Std } \\
\text { Error }\end{array}$ & T-Stat & $\mathrm{R}^{2}$ \\
\hline (Constant) & 6.699 & 1.333 & & \\
PEM & .091 & .114 & 5.025 & .182 \\
\hline
\end{tabular}

Keterangan : $\alpha=5 \%$

Sumber: SPSS 19.0 (2019), data diolah

Dari hasil estimasi pada tabel dapat dituliskan persamaan sebagai berikut : Pendapatan UMKM $=6.699+$ 0,091PEM

Dari hasil estimasi tersebut dapat diinterpretasi sebagai berikut:

a. Nilai konstanta atau a sebesar 6,699 (positif) mempunyai makna bahwa ketika tingkat pembiayaan dianggap bersifat konstan atau nol, maka pendapatan nasabah kelompok usaha perindustrian BMT Bima mengalami kenaikan sebesar 6.699 juta rupiah dalam satu tahun.

b. Koefisien regresi variabel pembiayaan (X) sebesar 0,091 (positif) hal ini didukung oleh uji $\mathrm{t}$ yang menunjukkan bahwa tidak ada pengaruh yang bermakna dari variabel pembiayaan terhadap variabel pendapatan bagi UMKM nasabah BMT Bima kelompok usaha perindustrian.

\section{Uji t}

Uji $\mathrm{t}$ digunakan untuk mengetahui pengaruh dari masing-masing variabel independen terhadap variabel dependen secara parsial

Tabel 4 Hasil uji t

\begin{tabular}{ccccl}
\hline Var & t-stat & Prob & t-tab & Kesimpulan \\
\hline PEM & 0,801 & .428 & 1,685 & Tidak signifikan \\
\hline Sumber: SPSS & 19.0 (2019), data diolah & &
\end{tabular}


Jurnal Ilmiah Akuntansi Universitas Pamulang - Vol. 9, No. 2 Juli 2021 - Setyawan \& Iswanaji

Hasil regresi diperoleh : $t_{\text {hitung }}=0,801<t_{\text {tabel }}=1,685$, maka hipotesa nol (Ho) diterima, hal ini berarti bahwa tingkat pembiayaan tidak berpengaruh positif terhadap tingkat pendapatan nasabah kelompok perindustrian BMT Bima Magelang.

\section{Uji $\mathbf{R}^{2}$}

Koefisien determinasi ini menunjukkan tingkat derajat keakuratan hubungan antara variabel independen dengan variabel dependen. Dari hasil regresi diperoleh nilai $R$ square adalah sebesar 0.182 yang berarti bahwa pendapatan UMKM BMT Bima kelompok usaha perindustrian dapat dijelaskan oleh variasi model dari pembiayaan sebesar $18,2 \%$ dan sisanya $81,8 \%$ dijelaskan oleh variabel-variabel lain di luar model tersebut. Nilai koefisien determinasi antara 0-1 dan bernilai positif (Kuncoro, 2011). Penelitian ini didukung oleh penelitian dari Hatmaka (2013) yang memperoleh hasil R square sebesar 38\%, di mana hasil tersebut menunjukkan pertumbuhan UMKM di Jatinom, Klaten, Jawa Tengah dijelaskan oleh variabel bebas pembiayaan, ketersediaan tabungan dan Enterprise Development Services.

\section{Pengaruh Pembiayaan Terhadap Pendapatan UMKM Kelompok Usaha Perindustrian BMT Bima Magelang.}

Berdasarkan hasil uji statistik, diketahui bahwa variabel pembiayaan memiliki nilai t-hitung yaitu 0,801 , sedangkan nilai sig. 0,428 , sehingga secara parsial variabel pembiayaan berpengaruh negatif dan tidak signifikan terhadap pendapatan UMKM. Hal ini tidak sejalan dengan penelitian Utami (2011) dan Litriani (2017) yang memperoleh hasil penelitian bahwa besarnya pembiayaan berpengaruh positif signifikan terhadap pendapatan.

Pembiayaan tidak berpengaruh positif dan signifikan terhadap pendapatan UMKM menunjukkan apabila pembiayaan yang diterima oleh pelaku UMKM tidak dapat digunakan untuk meningkatkan pendapatan UMKM. Pembiayaan yang diterima sebagai modal usaha masih digunakan untuk membiayai kehidupan keluarga, bukan semuanya digunakan untuk mengembangkan usaha. Hasil penelitian ini sejalan dengan Wijayanto (2003) yang menemukan bahwa pembiayaan yang diberikan BMT tidak memengaruhi perkembangan usaha.

\section{Peran Lembaga Keuangan Mikro Syariah (BMT) dalam Pengentasan Kemiskinan Melalui Baitul Mall dan Baitul Tamwil di BMT Bima Kabupaten Magelang.}

Kesejahteraan lahir batin merupakan kondisi yang diidamkan oleh manusia. Kondisi yang berlawanan dengan kesejahteraaan adalah kemiskinan, keadaan yang ingin diatasi dalam setiap proses pembangunan. Kemiskinan dipandang sebagai suatu kondisi seseorang atau sekelompok orang, laki-laki dan perempuan yang tidak terpenuhi hak- hak dasarnya secara layak untuk memperbaiki kehidupan yang bermartabat.

Salah satu upaya penanggulangan kemiskinan adalah dengan memutuskan rantai kemiskinan melalui pemberdayaan kelompok dengan melakukan pengembangan micro finance institutions (Lembaga Keuangan Mikro/LKM). LKM merupakan pendekatan terbaik sebagai upaya pemberdayaan dan pengembangan usaha mikro untuk menanggulangi kemiskinan serta meningkatkan pendapatan. 
Jurnal Ilmiah Akuntansi Universitas Pamulang - Vol. 9, No. 2 Juli 2021 - Setyawan \& Iswanaji

Pemahaman tentang profil kemiskinan dan penyebabnya merupakan prasyarat bagi ketepatan strategi pengentasan kemiskinan.

Kehadiran BMT sebagai lembaga keuangan mikro syariah yang dekat dengan masyarakat dalam memberi bantuan berupa pembiayaan sesuai prinsip syariah pada nyatanya memang membantu dalam mengurangi masalah permodalan terutama bagi para pelaku usaha atau UMKM yang membutuhkan dana dalam mendukung kegiatan perekonomian, hal ini ditunjukkan dengan syarat pengajuan yang mudah, margin keuntungan yang sesuai dengan kesepakatan, dan lain sebagainya. Oleh sebab itu, lambat laun modal bukan menjadi kendala dan masalah bagi UMKM. Hal ini sesuai dengan operasional BMT yaitu Baitul Tamwil. Peran strategis BMT dalam mengurangi kemiskinan dapat dilihat dar kegiatan ekonomi BMT yang mempunyai kegiatan sosial (Baitul Maal) dan kegiatan bisnis (at-Tamwil).

\section{KESIMPULAN DAN SARAN}

Berdasarkan hasil penelitian yang dilakukan. Maka dapat disimpulkan sebagi berikut:

1. Variabel pembiayaan tidak berpengaruh signifikan terhadap variabel pendapatan pada tahun 2018. Hal ini disebabkan karena masih ada beberapa nasabah UMKM yang menggunakan pembiayaan untuk kegiatan perekonomian pribadi.

2. BMT Bima mampu mengurangi kemiskinan melalui penyaluran dana ZISWAF (baitul maal) yaitu zakat, infak, shadaqah, dan wakaf kepada masyarakat yang membutuhkan di luar status sebagai nasabah.

Saran untuk nasabah agar menggunakan pembiayaan yang didapatkan dapat digunakan untuk semestinya agar meningkatkan pendapatan dari usaha yang dimiliki oleh para nasabah. Sedangkan untuk peneliti selanjutnya diharapkan dapat menggunakan beberapa daerah agar dapat menjadi pembanding dan masukan untuk daerah yang lain.

\section{DAFTAR PUSTAKA}

Abdad, M. Zaidi. (2003). Lembaga Perekonomian Umat di Dunia Islam. Bandung: Angkasa Bandung.

Amalia, Euis.(2009). Keadilan Distributif Dalam Ekonomi Islam. Jakarta: PT. Raja Grafindo Persada.

Effendi, Jaenal dan Widya Gina. (2014). Program Pembiayaan Lembaga Keuangan Mikro Syariah (LKMS) dalam Peningkatan Kesejahteraan Pelaku Usaha Mikro (Studi Kasus BMT Baitul Karim Bekasi). Jurnal AlMuzara"ah, Vol. 3, No. 1 (ISSN p: 2337-6333; e: 2355-4363). Hlm,3343.

Hatmaka, Herjuna Mai. (2013). Bagaimana Peran Lembaga Keuangan Baitul Maal Wat Tamwil Bagi Pertumbuhan Usaha Mikro, Kecil, Dan Menengah. Jurnal Ekonomi dan Studi Pembangunan. Volume14, Nomor 1, April 2013, hlm.35-43 
Jurnal Ilmiah Akuntansi Universitas Pamulang - Vol. 9, No. 2 Juli 2021 - Setyawan \& Iswanaji

http://www.dpr.go.id/id/undang-undang/2008/21/UU/Perbankan-Syariah

Itang. (2015). Faktor-Faktor Penyebab Kemiskinan. Jurnal Keislaman, Kemasyarakaan dan Kebudayaan Vol.16 No. 1 Januari-Juni 2015. Hlm $1-30$.

Kuncoro, Mudrajat. (2000). Ekonomi Pembangunan Teori, Masalah, dan Kebijakan. Yogyakarta: UPP STIM YKPN.

YKPN.

(2011). Metode Kuantitatif. Yogyakarta: UPP STIM

Litriani, E. (2017). Pengaruh Pembiayaan Modal Kerja Terhadap Pendapatan Usaha Nasabah Pada PT. Bank Syariah Mandiri Kantor Cabang Simpang Patal Palembang. I-Finance: a Research Journal on Islamic Finance, 3(2), 123-140.

Mankiw, N.G. (2006). Teori MakroEkonomi. Jakarta: Erlangga

Muhammad. (2016). Manajemen Pembiayaan Bank Syariah. Yogyakarta: UPP STIM YKPN.

\section{AMP YKPN}

. (2005). Manajemen Pembiayaan Bank Syariah. Yogyakarta: UPP

Prastiawati, F., \& Darma, E. S. (2016). Peran Pembiayaan Baitul Maal Wat Tamwil Terhadap Perkembangan Usaha dan Peningkatan Kesejahteraan Anggotanya dari Sektor Mikro Pedagang Pasar Tradisional. Journal of Accounting and Investment, 17(2), 197-208.

Sholihah, Siti, Lorentino Togar Laut dan Gentur Jalunggono. (2019). Analisis Pengaruh Produk Domestik Bruto (Pdb), Invetasi, Tenaga Kerja Terhadap Tingkat Kemiskinan Di Indonesia Tahun 2001-2010. DINAMIC : Directory Journal of Economic Volume 1 Nomor 2. Hlm159-167.

Soemitra, A. (2009). Bank dan Lembaga Keuangan Syariah. Jakarta: Kencana Prenada Media Group.

Suci, Y. R. (2017). Perkembangan UMKM (Usaha mikro kecil dan menengah) di Indonesia. Jurnal Ilmiah Cano Ekonomos, 6(1), 51-58.

Sumodiningrat, G., Santoso, B., Maiwan, M. (1998). "Kemiskinan: Teori, Fakta dan Kebijakan". Jakarta: IMPAC

Undang-Undang Nomor 20 tahun 2008 Tentang Usaha Mikro, Kecil dan Menengah.

Utami, A. M. (2011). Pengaruh pembiayaan mudharabah terhadap pendapatan BMT Bina Umat sejahtera Pondok Gede.

Wijayanto, J. (2003). Analisis Hubungan Kredit BMT Al-Fattah Terhadap Perkembangan Usaha Kecil Di Kecamatan Susukan Salatiga. Skripsi, Universitas Muhammadiyah Surakarta.

World Bank. (2010). "Making the New Indonesia Work fpr the Poor". The World Bank. 